\title{
Effect of Combined Application of Antibacterial Agents on the Efficacy of Voriconazole: Opinion and Thinking
}

\author{
Zhang Ligang, Duan Rong and Li Zhengxiang* \\ The Department of Pharmacy, General Hospital, Tianjin Medical University, Tianjin 300052, China
}

*Corresponding author: Li Zhengxiang, General Hospital, Tianjin Medical University, 154 Anshan Road, Heping District, Tianjin, China

\begin{tabular}{|c|c|}
\hline ARTICLE INFO & ABSTRACT \\
\hline Received: 彗 November 04, 2019 & This research was based upon the clinical data for patients with hematologic \\
\hline Published: November 13, 2019 & $\begin{array}{l}\text { malignance who had been receiving voriconazole injection and antibiotics in the } \\
\text { Department of Hematology, Tianjin Medical University General Hospital from May }\end{array}$ \\
\hline $\begin{array}{l}\text { Citation: Zhang Ligang, Duan Rong, } \\
\text { Li Zhengxiang. Effect of Combined } \\
\text { Application of Antibacterial Agents on } \\
\text { the Efficacy of Voriconazole: Opinion and }\end{array}$ & $\begin{array}{l}\text { 1, } 2018 \text { to April } 30,2019 \text {. The test group was treated with voriconazole injection in } \\
\text { combination with three or more antibacterial drugs, and the control group was treated } \\
\text { with voriconazole injection in combination with } 1-2 \text { antibacterial drugs. The sample } \\
\text { was matched by propensity score matching method, and the prognosis of the test } \\
\text { group and the control group was compared by antifungal effectiveness and incidence of } \\
\text { adverse drug reactions. }\end{array}$ \\
\hline
\end{tabular}
Thinking. Biomed J Sci \& Tech Res 22(5)2019. BJSTR. MS.ID.003810.
Keywords: Voriconazole; Antibacterial; Malignant blood disease

\section{Introduction}

With its high morbidity and mortality, Invasive fungal infection (IFI) has long been a major threat for patients with malignant blood disease (MBD), IFIs mainly occur in patients with acute myeloid leukemia, and the incidence rate is about 34.6-48.4\% [1,2]. Voriconazole is a new generation of triazole antifungal drugs. With merits of a broad antibacterial spectrum, prominent antifungal effect, and high bioavailability. It has a good preventive and therapeutic effects in Candida and Aspergillus fungal infections, and have become the first line of invasive Aspergillus infection [3]. In clinical use, voriconazole injection is often combined with antibacterial drugs. This study aimed to investigate the effect of voriconazole injection combined with three or more antibacterial agents on prophylaxis and treatment of hematological malignancies with invasive fungal infections.

\section{Objectives and Methods}

\section{General Information}

Retrospective collection and analysis of patients who were admitted to our department of Hematology and applied voriconazole injection combined with antibacterial drugs from May 1, 2018 to April 30, 2019. The test group was voriconazole injection combined with 3 or more antibacterial drugs, the control group was voriconazole injection combined with 1-2 antibacterial drugs.

\section{Inclusion or Exclusion}

Inclusion: Patients who were diagnosed with hematologic malignancies referring to "Diagnosis and treatment of hematologic malignancies", with the disease types classified according to ICD10 [4]. Patients who received voriconazole intravascular injection during hospitalization. Combination of antibacterial drugs during the application of voriconazole injection.

Exclusion: Non-malignant hematological diseases or patients with unclear diagnosis. No voriconazole injections during hospitalization. No antibacterial drugs were used during the application of voriconazole injection.

\section{Outcome Indicators}

Outcomes measured Included the effectiveness rate and the incidence of adverse events in two groups patients. Effective treatment per case is defined as an effective evaluation indicator for prevention and treatment, as referring to "the Diagnostic Criteria and Principles of Treatment for Invasive Fungal Diseases in Patients with Hematological/Malignant Tumors (Fifth Revision)" [5].

\section{Statistical Methods}

Data from the control and intervention groups was matched by the means of propensity score matching (PSM), with the caliper 
value was set to 0.03 and match between the same or similar groups. Once the measurement data satisfied the normal distribution, $t$ test would be performed and the mean \pm standard deviation $(x \pm s)$ was used. Otherwise, a rank sum test would be performed, being expressed by the interquartile range. Counted data was analyzed by $\chi 2$ test and the adoption rate (\%). $\mathrm{P}<0.05$ was considered statistically significant. All statistics were completed with SPSS 22.0 software.

\section{Result}

\section{General Comparison}

A total of 286 intention to treat patients were enrolled in the study, 169 in the experimental group and 117 in the control group.
NO significant difference existed in their age, gender, type of disease, chemotherapy regimen, past medical history, and purpose of medication $(\mathrm{P}>0.05)$. Length of hospitalization and occurrence of neutrophil deficiency time $\geq 7$ days in the experimental group were significantly higher for the test group compared to the control group, significant number $(\mathrm{P}<0.05)$; see Table 1 for details.

60 cases were left in each group after PSM. The age, sex, hospitalization time, disease type, chemotherapy, neutrophil deficiency time $\geq 7$ days, past medical history, medication purpose have no significant difference ( $P>0.05$ ). The baseline data of the two groups were balanced before being compared. matched samples were used for comparative analysis. See Table 1 for details.

Table 1: Comparison of baseline between study group and control group before and after PSM.

\begin{tabular}{|c|c|c|c|c|c|c|}
\hline \multirow[b]{2}{*}{ Variable } & \multicolumn{2}{|c|}{ Before PSM $(n=286)$} & \multirow[b]{2}{*}{ P value } & \multicolumn{2}{|c|}{ After PSM (n=120) } & \multirow[b]{2}{*}{ P Value } \\
\hline & $\begin{array}{l}\text { Test Group } \\
(\mathrm{n}=169)\end{array}$ & $\begin{array}{c}\text { Control Group } \\
(\mathrm{n}=117)\end{array}$ & & $\begin{array}{l}\text { Test Group } \\
(n=60)\end{array}$ & $\begin{array}{c}\text { Control Group } \\
(n=60)\end{array}$ & \\
\hline Age & $62(54,67)$ & $62(50.5,68.5)$ & 0.963 & $61(54,68)$ & $62(53,69)$ & 0.759 \\
\hline Gender (male) & $95(56.21)$ & $65(55.56)$ & 0.912 & $27(45.00)$ & $24(40.00)$ & 0.58 \\
\hline hospitalization time & $42(31,60)$ & $28(16,43.5)$ & 0 & $34(26,49)$ & $35(21,49)$ & 0.634 \\
\hline \multicolumn{7}{|c|}{ Type of Disease } \\
\hline WZZL & $19(11.24)$ & $8(6.84)$ & 0.21 & $4(6.67)$ & $7(11.67)$ & 0.343 \\
\hline EXZL & $150(88.76)$ & $109(93.16)$ & & $56(93.33)$ & $53(83.33)$ & \\
\hline Chemotherapy & $147(86.98)$ & $102(87.18)$ & 0.961 & $52(86.67)$ & $50(83.33)$ & 0.609 \\
\hline $\begin{array}{l}\text { Neutrophil deficiency } \\
\text { time } \geq 7 \text { days }\end{array}$ & $70(41.42)$ & $22(18.80)$ & 0 & $11(18.33)$ & $11(18.33)$ & 1 \\
\hline \multicolumn{7}{|c|}{ Past Medical History } \\
\hline hypertension & $43(25.44)$ & $36(30.77)$ & 0.322 & 11(18.33) & $11(18.33)$ & 1 \\
\hline diabetes & $30(17.75)$ & $17(14.53)$ & 0.47 & $11(18.33)$ & 11(18.33) & 1 \\
\hline Blood transfusion history & $29(17.16)$ & $24(20.51)$ & 0.473 & 11(18.33) & 11(18.33) & 1 \\
\hline \multicolumn{7}{|c|}{ Target Medication } \\
\hline Preventive medication & $28(16.57)$ & $23(19.66)$ & 0.502 & $11(18.33)$ & 11(18.33) & 1 \\
\hline Experience medication & $25(14.79)$ & $20(17.09)$ & 0.599 & $0(0.00)$ & $2(3.33)$ & 0.154 \\
\hline Diagnostic-driven medication & $104(61.54)$ & $71(60.68)$ & 0.884 & $45(75.00)$ & $45(75.00)$ & 1 \\
\hline Purpose of medication & $12(7.10)$ & $3(2.56)$ & 0.091 & $4(6.67)$ & $2(3.33)$ & 0.402 \\
\hline
\end{tabular}

\section{Effectiveness}

After PSM matching, the effective rate of the test group was $75 \%$, and the effective rate of the control group was $90 \%$. The difference was statistically significant $(\mathrm{P}<0.05)$. See Table 2 .

\section{Incidence of Adverse Reactions}

After PSM matching, the incidence of adverse reactions in the test group was $21.67 \%$, and the incidence of adverse reactions in the control group was $20 \%$. The difference was not statistically significant $(\mathrm{P}>0.05)$. See Table 2. 
Table 2: Comparison of prognosis between study group and control group after PSM.

\begin{tabular}{|c|c|c|c|}
\hline Prognostic Parameter & Test Group (n=60) & Control Group(n=60) & P Value \\
\hline Effectiveness & $45(75.00)$ & $54(90.00)$ & 0.031 \\
\hline The incidence of adverse events & $13(21.67)$ & $12(20.00)$ & 0.822 \\
\hline Abnormal liver function & $11(18.33)$ & $11(18.33)$ & 1 \\
\hline Visual Illusion & $1(1.67)$ & $1(1.67)$ & 0.315 \\
\hline Skin damage & $1(1.67)$ & $0(0.00)$ & 1 \\
\hline
\end{tabular}

\section{Discussion}

The widespread use of antibacterial drugs in clinical practice has led to the development of drug-resistant strains in patients, and the widespread use of broad-spectrum antibiotics can not only kill sensitive pathogens, but also kill normal strains and easily cause fungal infections [6]. However, long-term use of broad-spectrum antibiotics can lead to neutropenia, and reduce V's microbicidal ability in inhibiting growth mycelial cell walls in fungi, and not effectively destroy the fungal mycelial cell wall [7]. We are still working to include more individual level data for scaling up our researches to draw clearer and more generalized conclusions. However, our observation that the effectiveness of voriconazole is reduced after the combination of more than three antibacterial drugs, and we are doing further large-scale research, and our later conclusions will continue to be published in the form of papers. The views of this study would provide with clues in promoting clinical rational drug use from the perspective of both safety and efficacy.

\section{Acknowledgement}

None.

\section{Conflict of Interest}

No conflict of interest.

\section{ISSN: 2574-1241}

DOI: $10.26717 /$ BJSTR.2019.22.003810

Li Zhengxiang. Biomed J Sci \& Tech Res

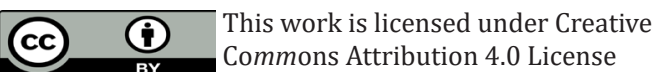

Submission Link: https://biomedres.us/submit-manuscript.php

\section{References}

1. Neofytos D, Lu K, Hatfield-Seung A, Blackford A, Marr KA, et al. (2013) Epidemiology, outcomes, and risk factors of invasive fungal infections in adult patients with acute myelogenous leukemia after induction chemotherapy. Diagn Microbiol Infect Dis 75(2): 144-159.

2. Tang JL, Kung HC, Lei WC, Yao M, Wu UI et al. (2015) High Incidences of Invasive Fungal Infections in Acute Myeloid Leukemia Patients Receiving Induction Chemotherapy without Systemic Antifungal Prophylaxis: A Prospective Observational Study in Taiwan. PLoS One 10(6): e0128410.

3. Zou Yong, Lin Congmeng, Liu Liang (2017) Clinical analysis of malignant hematological diseases complicated with invasive pulmonary fungal infection and observation of the efficacy of voriconazole[J]. China Modern Medicine Journal 19(06): 15-18.

4. Tenth Revision of the International Statistical Classification of Health Problems in Diseases and Related Issues.

5. (2017) Diagnostic criteria and principles of treatment for invasive fungal diseases in patients with hematological malignancy/malignant tumors (Fifth Revision). Clinical Medical Research and Practice (20): 201.

6. Aoun M, Crokaert F, Paesmans M, Autier P, Klastersky J (1998) Imipenem versus targeted therapy in cancer patients. Int J Antimicrob Agents 10(4): 263-270.

7. Christin L, Wysong DR, Meshulam T, Wang S, Diamond RD (1997) Mechanisms and target sites of damage in killing of Candida albicans hyphae by human polymorphonuclear neutrophils. J Infect Dis 176(6): 1567-1578.

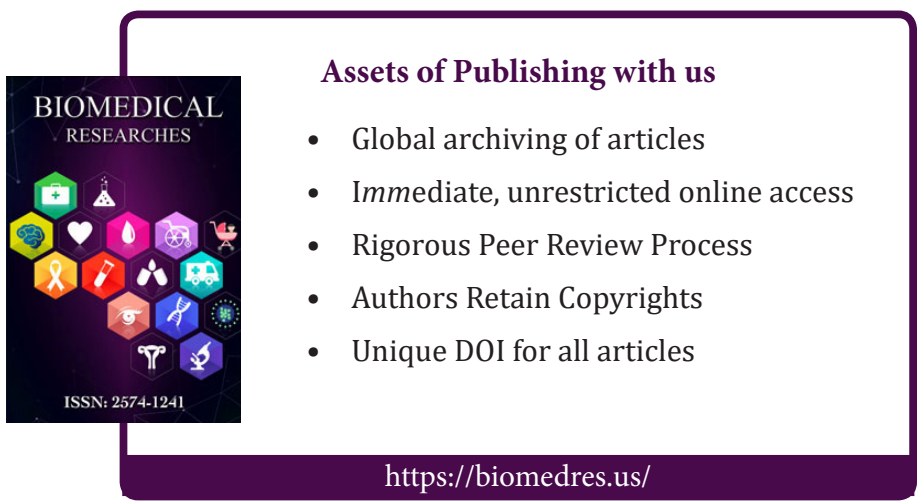

